\section{Facharztprüfung zur Erlangung des Facharzttitels FMH für Ophthalmologie}

Aufgrund des Weiterbildungsprogrammes, welches am 1. Januar 1999 in Kraft gesetzt wurde, ist die Teilnahme an der Facharztprüfung für diejenigen Kandidatinnen und Kandidaten Voraussetzung für die Erlangung des Facharzttitels Ophthalmologie, welche ihre Weiterbildung in Ophthalmologie bis am 31. Dezember 1999 nicht abgeschlossen hatten. Es empfiehlt sich, die Facharztprüfung frühestens im letzten Jahr der reglementarischen Weiterbildung abzulegen (Art. 22 WBO).
Ort: Bern

Datum: Freitag, 17. und Samstag, 18. November 2000

Prüfungsgebühr: Die Fachgesellschaft erhebt eine Prüfungsgebühr von Fr. 650.-.

Anmeldung: Verwaltungssekretariat der SOG, Fürsprecher Christoph Egli, Berneckerstrasse 26, 9435 Heerbrugg, Tel. 07172716 61, Fax 07172716 62, E-mail: e.r.law@openoffice.ch

Information: Prof. Dr. med. P. Leuenberger, Clinique d'Ophtalmologie, 22, rue Alcide-Jentzer, 1205 Genf, Tel. 02238283 64, Fax 02238283 82, E-mail: peter.leuenberger@hcuge.ch

Anmeldefrist: 8. September 2000

\section{Examen de spécialiste en vue de l'obtention du titre de spécialiste FMH en ophtalmologie}

Conformément au programme de formation postgraduée entré en vigueur le $1^{\mathrm{er}}$ janvier 1999, la participation à l'examen de spécialiste est une condition requise pour les candidats à l'obtention du titre de spécialiste FMH en ophtalmologie qui n'avaient pas terminé leur formation postgraduée en ophtalmologie le 31 décembre 1999. Il leur est recommandé de passer l'examen de spécialiste au plus tôt durant la dernière année de leur formation postgraduée réglementaire (art. 22 RFP).
Lieu: Berne

Date: Vendredi, le 17 et Samedi, le 18 novembre 2000

Taxe d'examen: La société de discipline médicale prélève une participation aux frais de Fr. 650.-.

Inscription: Secrétariat administratif de la SSO, Christoph Egli, avocat, Berneckerstrasse 26, 9435 Heerbrugg, tél. 07172716 61, fax 07172716 62, e-mail: e.r.law@openoffice.ch

Information: Prof. Dr P. Leuenberger, Clinique d'Ophtalmologie, 22, rue Alcide-Jentzer, 1205 Genève, tél. 02238283 64, fax 02238283 82, e-mail: peter.leuenberger@hcuge.ch

Délai d'inscription: le 8 septembre 2000 